\title{
Photografting of PET Fabrics with Vinyl Pyrrolidone and Acryloyl Morpholine Monomers
}

\author{
Weiwei Huang and Jinho Jang
}

Dept. of Nano-Bio Textile Engineering, Kumoh National Institute of Technology, Kumi 730-701, Korea

(Received: September 4, 2008/Revised: October 9, 2008/Accepted: October 20, 2008)

\begin{abstract}
PET fabrics were photografted under continuous UV irradiation with vinyl pyrrolidone (VP) and acryloylmorpholine(ACMO) as monomers and benzophenone as a hydrogen-abstractable photoinitiator. ACMO can be grafted onto the PET fabrics more efficiently than VP. The grafted PET surfaces were characterized by ATR, ESCA, SEM and zeta potential measurement. ATR and ESCA analysis indicated significant alterations on chemical structure and atomic composition on the surface of the grafted fabrics, where nitrogen content increased with increasing grafting yield. SEM images showed that the fabric surface was covered with the grafted polymers. The zeta potentials and the water wettability of the grafted PET increased with grafting. Also the photografted fabrics showed an increased dyeablity to reactive dyes and increased affinity to various iodine species which imparted anti-bacterial properties.
\end{abstract}

Keywords: photografting, VP, ACMO, dyeability, antimicrobial activity

\section{Introduction}

Grafting hydrophilic groups onto PET fabrics is one of the effective ways for improving its inherent deficiency such as hydrophobic property, low dyeablity, electrostatic charging, etc. Grafting copolymerization can be induced by $\mathrm{EB}$, UV irradiation, ionizing radiation, or wet thermal treatments. Many researchers have studied on introduction of various functional groups including carboxylic acid, hydroxy, or amide onto PET using various methods ${ }^{1-7)}$.

$N$-vinyl-2-pyrrolidone (VP) is a hydrophilic and nonionic monomer, and the radical polymerization of $\mathrm{VP}$ can be easily initiated through heat or photons ${ }^{8,99}$. Cohen et al. studied the free radical grafting of VP onto silica ${ }^{10)}$. Ishihara et al. grafted VP onto polyethylene film surface using photo-induced polymerization technique for adhesion resistance to blood cells ${ }^{11)}$. VP and maleic anhydride were photografted onto PP film via a charge-transfer-complex mechanism to enhance its hydrophilicity, and the grafted film was complexed with iodine to give antimicrobial property $^{12)}$.
Acryloylmorpholine (ACMO) is a reactive monomer capable of undergoing free radical polymerization. ACMO contains such good properties as the followings ${ }^{13)}$ : quick polymerization rate, low viscosity, low primary skin irritation index (PII < 0.5), odorless and colorless. ACMO has a nitrogen atom which prevents oxygen inhibition of polymerization. ACMO copolymer was synthesized materials for metal ion binding ${ }^{14)}$. But few study was reported on the surface photografting of ACMO onto PET fabrics .

In this study, plain weave PET fabric was modified with a hydrophilic monomer of VP or ACMO by UVinduced graft polymerization. Hydrogen abstractable benzophenone (BP) was used as a photoinitiator.

The grafting mechanism and grafting behavior was investigated. The grafted PET fabrics was characterized by ATR, ESCA, and FE-SEM analysis.

Their wettablility, surface zeta potentials, and reactive dyeability were investigated. Also the grafted PET fabrics were complexed with iodine to enhance its antibacterial property. 


\section{Experimental}

\subsection{Materials and chemicals}

Plain weave PET fabrics $\left(76.8 \mathrm{~g} / \mathrm{m}^{2}\right)$ were used for the study. Water-soluble monomers of 1-vinyl-2-pyrrolidone (VP) and 4-acryloylmorpholine (ACMO) were supplied by Aldrich Chemical Co. Benzophenone(BP), a hydrogen-abstractable photoinitiator, was also provide supplied by Aldrich Chemical Co. and Triton X100, a wetting agent, was obtained from Yakuri Pure Chemical Co. Ltd. The chemical structures of the monomers and BP are shown in Scheme 1. Reactive dyes of Lanasol Red 6G (C.I. Reactive Red 84) and Lanasol Blue 3R (C.I. Reactive Blue 50) were used for dyeing. The chemical structures of dyes are shown in Scheme 2.

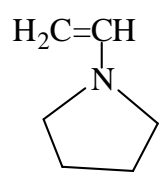

(a)<smiles>C=CC(=O)N1CCOCC1</smiles>

(b)
Scheme 1. Molecular structures of (a) VP and (b) ACMO.

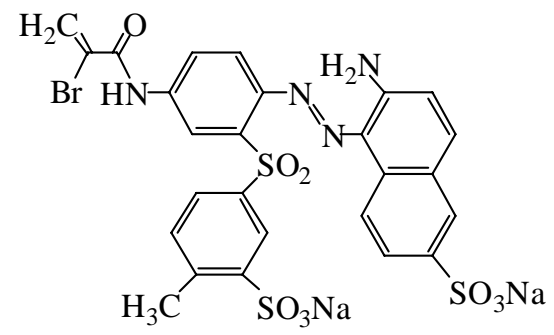<smiles>Cc1c(NC(=O)C(Br)CBr)cc(Nc2cc(S(N)(=O)=O)c(N)c3c2C(=O)c2ccccc2C3=O)c(C)c1S(N)(=O)=O</smiles>

(b)

Scheme 2. Molecular structures of (a) C.I. Reactive Red 84 and (b) C.I. Reactive Blue 50.

\subsection{Surface photografting of PET}

PET fabrics were immersed into the grafting formulation containing monomer, BP and Triton X100 and the wetted fabric was subsequently squeezed to a wet pick up of about $60 \%$ using a padding mangle. A UV apparatus enclosing a D-bulb (a metal doped mercury lamp) of $80 \mathrm{~W} / \mathrm{cm}$ intensity was used for UV irradiation. UV energy was controlled by adjusting the conveyor speed and passing cycles of a conveyor belt. After irradiation, the fabrics were throughly extracted first with acetone and subsequently with water to remove unreacted monomer, PI, and soluble homopolymer. G\% and GE\% represent the grafting yield and grafting efficiency respectively, which were calculated from the following equations:

$$
\begin{gathered}
\mathrm{G} \%=\left(\mathrm{W}_{3}-\mathrm{W}_{1}\right) / \mathrm{W}_{1} \times 100 \\
\mathrm{GE} \%=\left(\mathrm{W}_{3}-\mathrm{W}_{1}\right) /\left(\mathrm{W}_{2}-\mathrm{W}_{1}\right) \times 100
\end{gathered}
$$

where, $\mathrm{W}_{1}$ is weight of original fabric, $\mathrm{W}_{2}$ and $\mathrm{W}_{3}$ are weights of the treated fabric after UV irradiation and after solvent extraction respectively.

\subsection{Surface characterization}

The PET fabrics were analyzed by ATR apparatus attached with a ZnSe crystal using a Tensor 27 spectrophotometer (Bruker Optics). ESCA (Electron Spectroscopy for Chmical Analysis) was performed on the PET fabrics using a Quantera SXM spectrophotometer (ULVAC-PHI). The elemental ratios of $\mathrm{O}_{1 \mathrm{~s}}$ or $\mathrm{N}_{1 \mathrm{~s}}$ to $\mathrm{C}_{1 \mathrm{~s}}$ were calculated. A field-emission scanning electron microscope (JEOL JSM-6580F, Japan) was used to observe the surface morphology of the grafted PET fabrics. Surface zeta potentials of the PET fabrics were measured using electrophoretic light scattering spectrophotometer (ELS-300, OTSUKA, Japan), which was carried out with $10 \mathrm{mM} \mathrm{NaCl}$ at $\mathrm{pH} 7$.

\subsection{Wettability and reactive dyeability}

Water wetting time on the fabrics were tested to check its wettability of the modified surfaces. The wetting time was the time that a drop of water was totally absorbed into the fabric. Each sample was carried out three times or more to make an average. 
The grafted PET fabrics were dyed with reactive red and blue dyes. The dyeing were carried out at $60^{\circ} \mathrm{C}$ for $90 \mathrm{~min}$ using a IR dyeing machine (DL-6000, Starlet Co. Ltd). The dyeing bath contained dyes of 0.5 to $10 \%$ owf and $50 \mathrm{~g} / \mathrm{L} \mathrm{NaCl}$ under $\mathrm{pH} 7$. After the dyeing, the dyed fabrics were washed to remove the unfixed dyes first with 2 wt\% detergent solution (ECE Phosphate REF DET B) at $50^{\circ} \mathrm{C}$ and subsequently with distilled water at $50^{\circ} \mathrm{C} . \mathrm{K} / \mathrm{S}$ was calculated from the reflectance at $\lambda_{\text {max }}$ using a reflectance spectrophotometer (Gretag Macbeth, Coloreye 3100).

\section{5 lodine complexing and Anti-bacterial test}

Grafted PET fabrics were used to complex with iodine solution. The complexation was carried out with $5 \%$ iodine ethanol solution at $70^{\circ} \mathrm{C}$ for 5 hours. After complexation, the fabrics were washed first by heptane and then by ethanol to remove the uncomplexed iodine. The antibacterial property of the complexed fabrics was tested. The anti-bacterial property was tested by JIS L 1902:2002. The types of bacterium used were gram-positive Staphylococcus Aureus (ATCC 6538) and gram-negative Klebsiella pneumoniae (ATCC 4352).

Bacteriostatic activity value(S) and bacteriostatic rate were used to evaluate the anti-bacterial property which is calculated by the following equation:

Bacteriostatic activity vatjue $\# / \log \left(\mathrm{M}_{\mathrm{b}} / \mathrm{M}_{\mathrm{c}}\right)$

Bacteriostatic rate $=$

$$
M_{b}>100
$$

where, $\mathrm{M}_{\mathrm{b}}$ and $\mathrm{M}_{\mathrm{c}}$ are the bacteria numbers on the control sample and the test samples after growing for 18 hours respectively.

\section{Results and discussion}

\subsection{Grafting yield (G\%) and Grafting efficiency (GE\%)}

Fig. 1, 2 and Table 2 showed the G\% and GE\% of VP or ACMO grafting with different UV energy, monomer and BP concentrations respectively. In case of VP, higher UV energy enhanced both G\% and GE\% until the UV energy reached $55 \mathrm{~J} / \mathrm{cm}^{2}$. ACMO | 30 | www.ksdf.or.kr seemed to be grafted more easily than VP, where a G\% above 50\% was obtained with as low as $5 \mathrm{~J} / \mathrm{cm}^{2}$ (Fig. 1). The reactivity of ACMO seem to be much higher than $\mathrm{VP}^{6}$. Both $\mathrm{G} \%$ and $\mathrm{GE} \%$ of both monomers increased with increasing monomer concentration (Fig. 2) because more monomers were available for the grafting when fabrics were padded with higher monomer concentration. With increasing BP concentration, both G\% and GE\% increased for both monomers(Table 1).

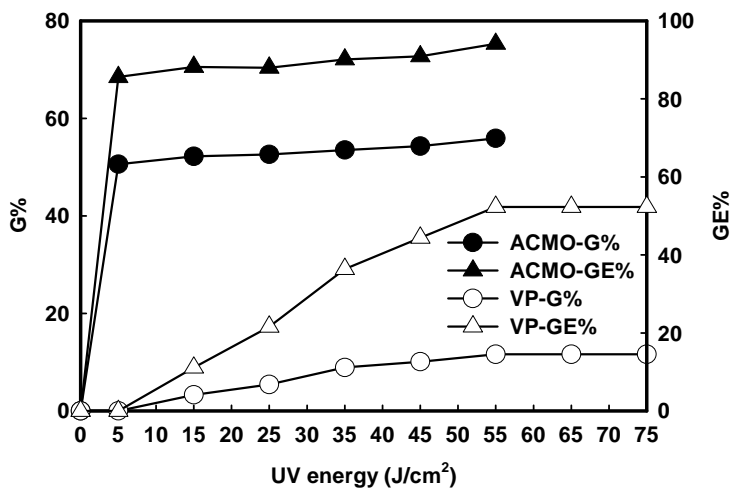

Fig. 1. Effect of the UV energy on the grafting $A C M O$ and VP (Monmer: 100\%, BP: 30\%owm).

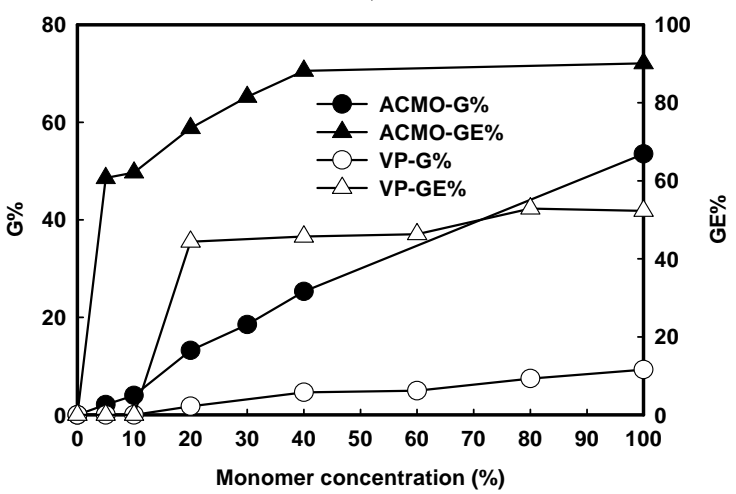

Fig. 2. Effect of the monomer concentration on the grafting $\mathrm{ACMO}$ and VP (BP: 30\%owm, UV energy: $35 \mathrm{~J} / \mathrm{cm}^{2}$ for $A C M O$ and $55 \mathrm{~J} / \mathrm{cm}^{2}$ for VP).

Table 1. Effects of BP concentration on the grafting of $V P$ and $A C A O$ (UV energy: $55 \% \mathrm{~m}^{2}$ for VP and $25 \mathrm{~J} / \mathrm{cm}^{2}$ for ACMO)

\begin{tabular}{|c|c|c|c|c|}
\hline \multirow{2}{*}{$\begin{array}{c}\text { BP } \\
(\% \text { owm })\end{array}$} & \multicolumn{2}{|c|}{ VP (100\%owf) } & \multicolumn{2}{|c|}{ ACMO (20\% owf) } \\
\hline & $\mathrm{G} \%$ & GE\% & $\mathrm{G} \%$ & GE\% \\
\hline 0 & 3.4 & 36.3 & 1.8 & 60 \\
\hline 5 & 8.1 & 46.3 & 10.3 & 81.9 \\
\hline 10 & 9.6 & 43.8 & 11.1 & 79.7 \\
\hline 20 & 10.4 & 50.4 & 12.0 & 77.4 \\
\hline 30 & 11.6 & 52.3 & 13.3 & 85.1 \\
\hline 40 & 9.1 & 40.3 & 14.4 & 75.6 \\
\hline
\end{tabular}


A higher BP concentration than $30 \%$ owm(on the weight of monomer) can not show an appreciable increase in the grafting probably because of the recombination of $\mathrm{BP}$ radiacals and the radicals generated on the PET surface ${ }^{15)}$.

\subsection{Surface characterization}

Fig. 3 showed the IR spectra of the grafted PET fabrics. The grafted PVP and ACMO showed the stretching vibration bands of $\mathrm{C}=\mathrm{O}$ at $1660 \mathrm{~cm}^{-1}$ and $1637 \mathrm{~cm}^{-1}$ respectively. The subtracted spectra of the VP-grafted PET fabrics, the increased peaks at $1658 \mathrm{~cm}^{-1}, 1429 \mathrm{~cm}^{-1}$, and $1269 \mathrm{~cm}^{-1}$ were assigned to $\mathrm{C}=\mathrm{O}, \mathrm{C}-\mathrm{H}$ and $\mathrm{C}-\mathrm{N}$ bonds in the grafted poly vinylpyridine respectively ${ }^{16,17)}$. In the case of ACMO grafting, the strong peaks located at $1629 \mathrm{~cm}^{-1}$ and $1263 \mathrm{~cm}^{-1}$ could correspond to the $\mathrm{C}=\mathrm{O}$ and $\mathrm{C}-\mathrm{N}$ stretching vibrations in the grafted ACMO repectively ${ }^{18)}$.

Also ESCA analysis of untreated and grafted PET fabrics were given in Table 2. The decreased intensity of carbon and oxygen atoms and increased $\mathrm{N}_{1 \mathrm{~s}}$ peaks at 399.7 and $400.2 \mathrm{eV}$ for VP and ACMO grafting respectively substantiated the presence of grafted polymers on the surface of the grafted PET.

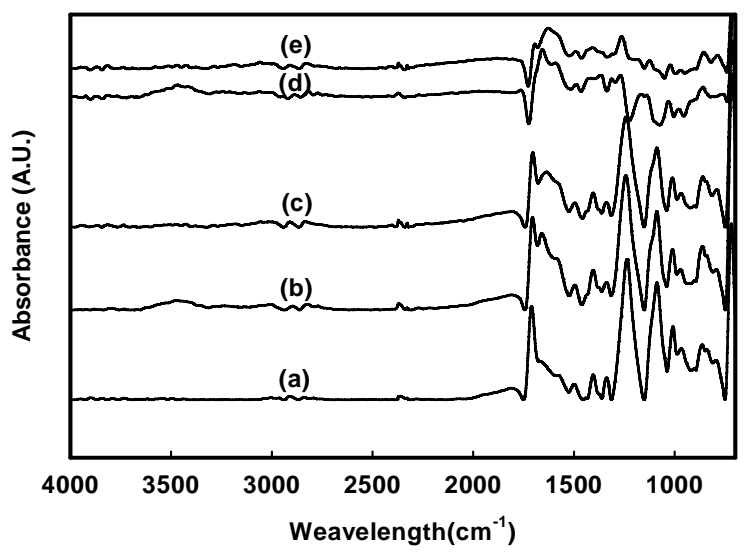

Fig. 3. IR spectra of (a) untreated, (b) VP grafted $(11.6 \% \mathrm{G})$, (c) ACMO grafted $(13.3 \% \mathrm{G})$, (d) subtracted spectra of (b) with (a), and (e) subtracted spectra of (c) with (a).
The atom ratio of $\mathrm{N}_{1 s} / \mathrm{C}_{1 \mathrm{~s}}$ increased with the increase with the grafting. The SEM images of VP and ACMO grafted PET are shown in Fig. 4. Fibers are almost coated with the grafted polymer with the increase in G\%. Especially in the ACMO grafted PET $(25.3 \% \mathrm{G})$, fiber structure disappeared due to the complete covering of grafted polymer, indicating that the monomers can gave a homogeneous grafting. The surface zeta potentials of VP or ACMO grafted PET fabrics were tested at $\mathrm{pH}$ 7. In Fig. 5, the data $\left({ }^{\circ}\right.$, ) at the ordinate are the zeta potentials of UV-irradiated PET $\left(35 \mathrm{~J} / \mathrm{cm}^{2}\right.$ for ACMO grafting and $55 \mathrm{~J} / \mathrm{cm}^{2}$ for VP grafting). With the grafting of VP and ACMO, the zeta potential increased compared to the UV- irradiated samples. This may be due to the screening effect of the grafted polymerd on the surface of the fabrics.

While both monomers are non-ionic hydrophilic monomer, the grafted surface reduced the negative charge caused by the UV irradiation ${ }^{18)}$ with the increase in $\mathrm{G} \%$.

\subsection{Wettability and reactive dyeability}

Both VP and ACMO contained hydrophilic groups of $\mathrm{C}=\mathrm{O}$ and $\mathrm{C}-\mathrm{N}$ in the molecular structures and both the polymeric VP and ACMO are water-soluble. The wettability of the grafted PET fabrics with either VP or ACMO is shown in Fig. 6. Water wetting time deceased remarkably with both VP and ACMO grafting and it had a maximum decrease at $5.8 \% \mathrm{G}$ and $13.2 \% \mathrm{G}$ for $\mathrm{VP}$ and $\mathrm{ACMO}$, respectively. This may be due to the gel-blocking effect of the grafted chains on the surface above the grafting yield.

The dyeability of the grafted fabrics to reactive dyes was also investigated. Fig. 7 and Fig. 8 showed the K/S changes of VP and ACMO grafted PET fabrics dyed by C.I Reactive Red 84 (a) and C.I. Reactive Blue 50 (b). While both the untreated and UV irradiated PET fabrics had no dyeability to reactive dyes, grafted fabrics showed higher dyeability with increasing dye concentration.

Table 2. Chemical compositions of untreated, ACMO grafted and VP grafted PET fabrics

\begin{tabular}{|c|c|c|c|c|c|}
\hline $\mathrm{G} \%$ & $\mathrm{C}_{1 \mathrm{~s}}(\%)$ & $\mathrm{O}_{1 \mathrm{~s}}(\%)$ & $\mathrm{N}_{1 \mathrm{~s}}(\%)$ & $\mathrm{O}_{1 \mathrm{~s}} / \mathrm{C}_{1 \mathrm{~s}}(\%)$ & $\mathrm{N}_{1 \mathrm{~s}} / \mathrm{C}_{1 \mathrm{~s}}(\%)$ \\
\hline Untreated & 75.2 & 24.8 & - & 33.0 & - \\
\hline$V P(11.6)$ & -68.0 & 25.4 & 6.6 & 37.4 & 9.7 \\
\hline $\operatorname{ACMO}(13.2)$ & 68.8 & 24.2 & 7.0 & 35.2 & 10.2 \\
\hline
\end{tabular}




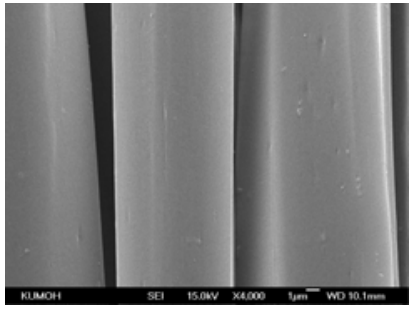

(a)

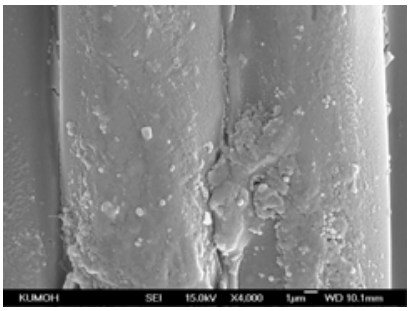

(b)

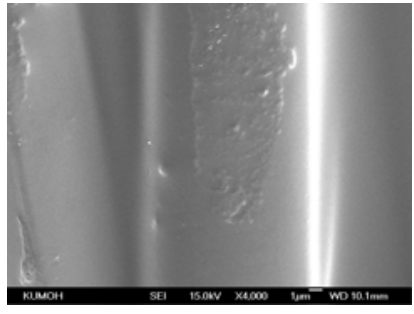

(c)

Fig. 4. SEM images of (a) untreated and grafted PET fabric with (b) VP (11.6\%G) and (c)ACMO (25.3\%G).

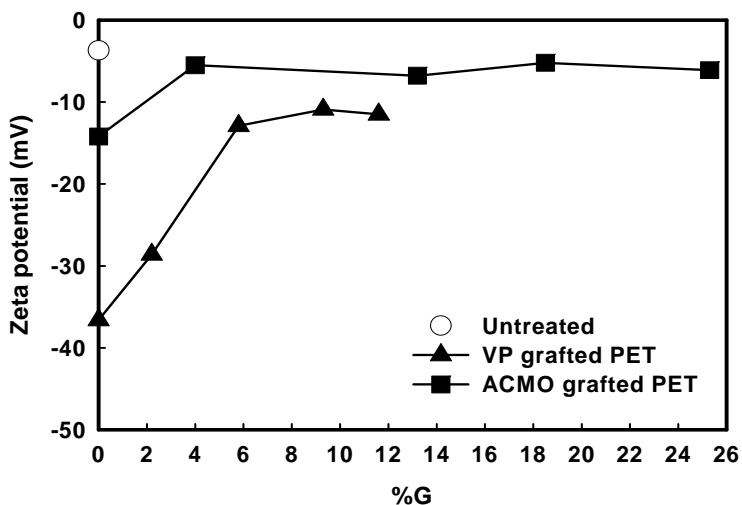

Fig. 5. Surface zeta potentials of untreated and grafted PET fabrics.

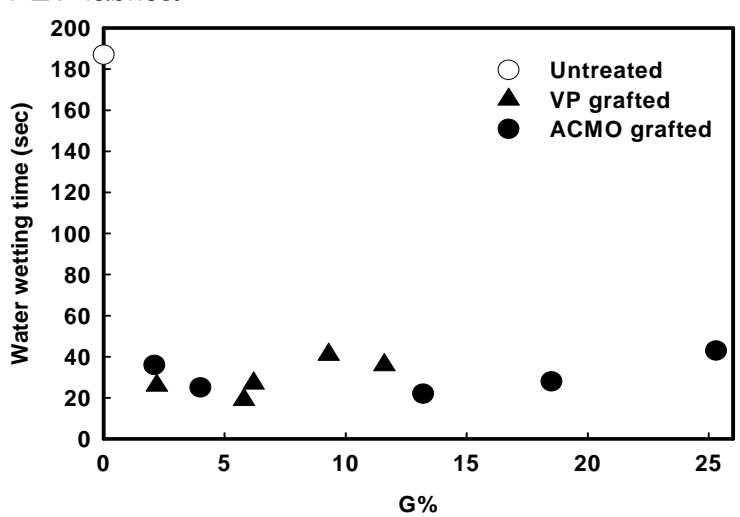

Fig. 6. Water wetting times of untreated and grafted PET fabrics.

In case of C.I. Reactive Red 84, 5\%owf and $2 \%$ owf were required to obtain highest $\mathrm{K} / \mathrm{S}$ for the ACMO-grafted PET and the VP-grafted PET, respectively. The dyeability of the grafted fabrics to C.I. Reactive Blue 50 showed similar tendency with lower $\mathrm{K} / \mathrm{S}$ compared with the red dye. However deep color shade can not be obtained even with higher dye concentration because only the weak electrostatic interactions can occur between the tertiary amines in the grafted VP or ACMO and the anionic reactive dyes.

| 32 | www.ksdf.or.kr

\section{4 lodine complexing and Anti-bacterial test}

The iodine complexation of the grafted PET fabrics either VP or ACMO were carried out to impart anti-bacterial property to PET fabrics. Table 3 showed the iodine absorption by the grafted PET fabrics. The peaks at $227 \mathrm{~nm}, 291 \mathrm{~nm}$ and $360 \mathrm{~nm}$ were assigned to $\mathrm{I}(227 \mathrm{~nm})$ and $\mathrm{I}_{3}{ }^{-}(291 \mathrm{~nm} \text { and } 360 \mathrm{~nm})^{19)}$ and all peaks decreased after the complexation of the grafted PET fabrics. Table 4 shows the anti-bacterial activity results.
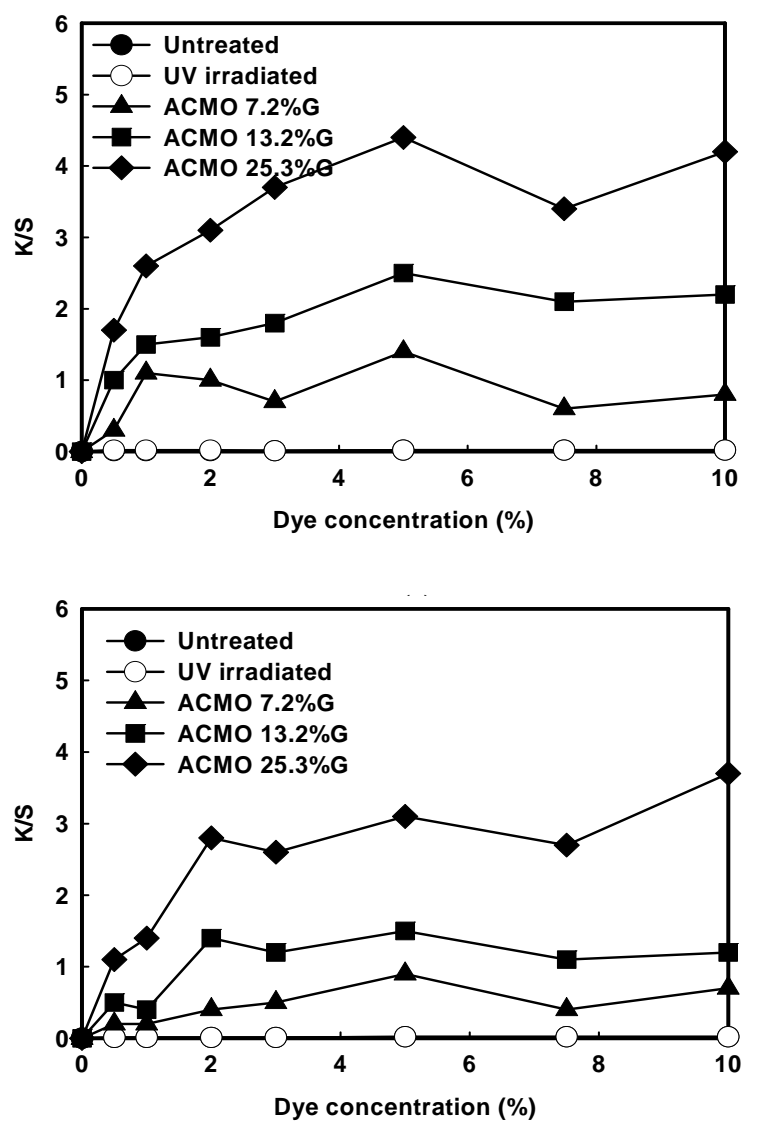

(b)

Fig. 7. K/S values of grafted PET fabrics with ACMO: (a) C.I. Reactive Red 84, (b) C.I. Reactive Blue 50. 


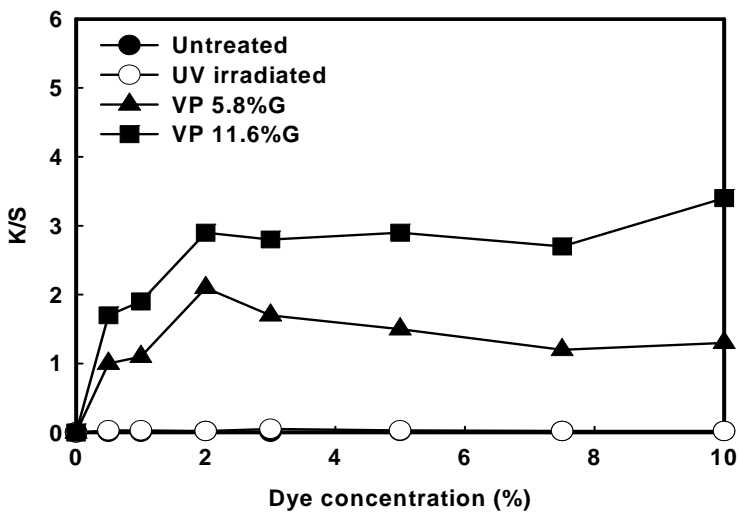

(a)

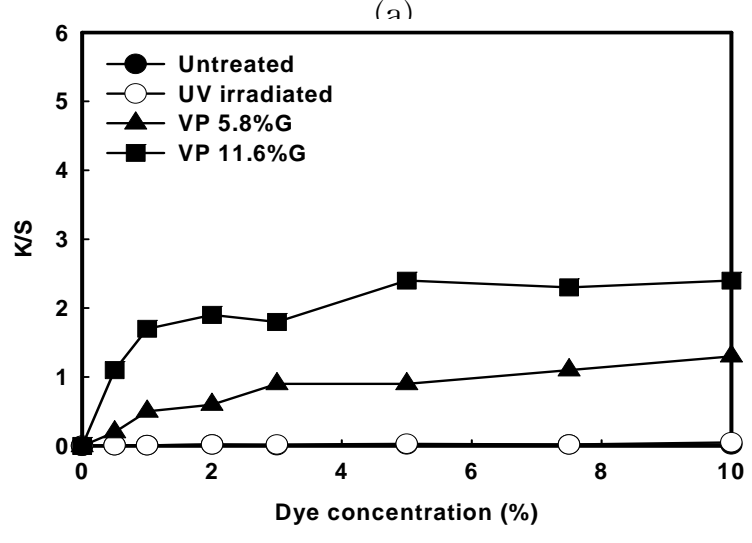

(b)

Fig. 8. K/S values of the grafted PET fabrics with VP: (a) C.I. Reactive Red 84, (b) C.I. Reactive Blue 50.

Table 3. Iodine absorption of the complexed PET fabrics

\begin{tabular}{ccccc}
\hline Fabrics & G\% & $227 \mathrm{~nm}$ & $291 \mathrm{~nm}$ & $360 \mathrm{~nm}$ \\
\hline Control & - & 1.08 & 0.72 & 0.42 \\
\hline Untreated & - & 0.95 & 0.60 & 0.34 \\
\hline $\mathrm{UV}\left(55 \mathrm{~J} / \mathrm{cm}^{2}\right)$ & - & 0.90 & 0.57 & 0.33 \\
& 5.8 & 0.84 & 0.54 & 0.31 \\
$\mathrm{VP}$ & 9.3 & 0.83 & 0.52 & 0.29 \\
\hline & 11.6 & 0.76 & 0.45 & 0.27 \\
& 7.2 & 0.84 & 0.56 & 0.28 \\
ACMO & 13.2 & 0.82 & 0.51 & 0.29 \\
\hline & 25.3 & 0.70 & 0.42 & 0.24
\end{tabular}

While untreated PET showed substantial antimicrobial activity against $S$. Aureus only, all the treated PET fabrics had a bacteriostatic activity value higher than 5.8 for S. Aureus and 5.9 for K. Pneumoniae.

Bacteriostatic rate higher than $99.9 \%$ was observed for all the treated fabrics. Previous study reported that the $\mathrm{I}, \mathrm{IO}^{-}$or $\mathrm{I}_{3}^{-}$complexed on the VP grafted PP film have a good anti-bacterial property because the iodines on the film can penetrate into microbial cell leading to halogen-induced denaturation of protein and the related enzymes ${ }^{12)}$.

The results indicated that the grafting without complexation may be enough for anti-bacterial property.

\section{Conclusions}

Water soluble monomers of VP and ACMO were used to modify the PET fabric by continuous surface photografting. ACMO was more facile to be grafted onto the PET fabrics than VP.

ATR, ESCA, SEM analysis proved the successful photografting of the monomers. The surface zeta potentials of the grafted PET fabrics increased with either ACMO or VP grafting. Wettability and the dyeability of the grafted PET fabrics improved with both grafting.

The grafted PET fabrics became complexed with various iodine species more easily and the antibacterial activity test results showed that the grafting of PET with VP or ACMO even without iodine complexation was enough to impart excellent anti -bacterial property for both gram-positive and gramnegative bacteria.

\section{Acknowledgement}

This work was supported by grant No. RTI04-01-04 from the Regional Technology Innovation Program of the Ministry of Knowledge Economy (MKE).

Table 4. The bacteriostatic activity value(bacteriostatic rate) of the PET fabrics

\begin{tabular}{cccccc}
\hline Bacteria type & untreated & VP & ACMO & VP-Iodine & ACMO-Iodine \\
& & $>5.8$ & $>5.8$ & $>5.8$ & $>5.8$ \\
\hline S. Aureus & $1.6(97.7 \%)$ & $(99.9 \%)$ & $(99.9 \%)$ & $(99.9 \%)$ & $(99.9 \%)$ \\
& & $>5.9$ & $>5.9$ & $>5.9$ & $>5.9$ \\
\hline K. Pneumoniae & $0(0 \%)$ & $(99.9 \%)$ & $(99.9 \%)$ & $(99.9 \%)$ & $(99.9 \%)$
\end{tabular}

J. of the Korean Soc. of Dyers and Finishers, Vol. 20, No. 5 | 33 | 


\section{References}

1. E. Uchida, H. Iwata, and Y. Ikada, Surface Structure of Poly(ethyleneerephthalate) Film Grafted with Poly(methacrylic acid), Polymer, 41, 3609-3614 (2000).

2. C. He, and Z. Gu, Studies on Acrylic acid-grafted Polyester Fabrics by Electron Beam Preirradiation Method. I. Effects of Process Parameters on Graft Ratio and Characterization of Grafting Products, J. Appl. Polym. Sci., 89, 3931-3938(2003).

3. H. Mirzadeh, M. Dadsetan, and N. SharifiSanjani, Platelet Adhesion on Laser-Induced Acrylic acid-grafted Polyethylene Terephthalate, J. Appl. Polym. Sci., 86, 3191-3196(2002).

4. B. Gupta, C. Plummer, I. Bisson, P. Frey, and J. Hilborn, Plasma-induced Graft Polymerization of Acrylic acid onto Poly(ethyleneterephthalate) Films: Characterization and Human Smooth Muscle Cell Growth on Grafted Films, Biomaterials, 23, 863871(2002).

5. Y. C. Nho, and O. H. Kwon, Blood Compatibility of AAc, HEMA, and Cellulose Film, Radiation Physics and Chemistry, 66, 299-307(2003).

6. L. M. Ferreiraa, A. N. Falcão, and M. H. Gilb, Elemental and Topographic Characterization of LDPE Based Copolymeric Films Obtained by Gammairradiation, Nucl. Instr. and Meth. in Phys. Res B, 265, 193-197(2007).

7. M. X. Hua, Q. Yang, and Z. K. Xua, Enhancing the Hydrophilicity of Polypropylene Microporous Membranes by the Grafting of 2-Hydroxyethyl Methacrylate via a Synergistic Effect of Photoinitiators, J. Membr. Sci., 285, 196-205(2006).

8. G. M. Kline, Polyvinylpyrrolidone, Mod. Plast. November, 157 161(1945).

9. E. Senogles, and R. Thomas, Polymerization Kinetics of $\bar{N}$-vinyl Pyrrolidone, J. Polym. Sci. Symp., 49, 203 210(1975).

10. M. Chaimberg, R. Parnas, and Y. Cohen, Graft
Polymerization of Polyvinylpyrrolidone onto Silica, J. Appl. Polym. Sci., 37, 2921 2931(1989).

11. K. Ishihara, Y. Iwasaki, S. Ebihara, Y. I. Shindo and N. Nakabayashi, Photoinduced Graft Polymerization of 2-Methacryloyloxyethyl Phosphorylcholine on Polyethylene Membrane Surface for Obtaining Blood Cell Adhesion Resistance, Colloids Surf. B, 18, 325-335(2000).

12. C. M. Xing, J. P. Deng, and W. T. Yang, Surface Functionalization of Polypropylene Film via UVInduced Photografting of N-Vinylpyrrolidone/Maleic Anhydride Binary Monomers, Macromol Chem. Phys., 206, 1106-1113(2005).

13. J. A. Dougherty, L. I. Lynch, and L. Mahamoud, Acryloyl Morpholine for UV Curing, Radtech Report, May/June, 2007.

14. B. L. Rivas, A. Maureira and K. E. Geckeler, Novel Water-soluble Acryloylmorpholine Copolylmers: Synthesis, Characterization, and Metal Ion Binding Properties, J. Appl. Polym. Sci., 101, 180185(2006).

15. R. Schwalm, UV coating, pp.117-118, 2007.

16. Z. M. Liu, Z. K. Xu, J. Q. Wang, J. Wu, and J. J. Fu, Surface Modification of Polypropylene Microfiltration Membranes by Graft Polymerization of N-vinyl-2-pyrrolidone, Euro. Polym. J., 40, 20772087(2004).

17. J. Z. Yi, and S. H. Goh, Interactions in Miscible Blends and Complexes of Poly(N-acryloylmorpholine) with Poly(p-vinylphenol), Polymer, 43, 4515-4522 (2002).

18. J. Jang and J. A. Son, Cationization of PET Fabrics via Continuous Photografting of [3-(Methacryloylamino) propyl]trimethylammonium Chloride, Text. Sci. Eng., 44, 312-318(2007).

19. N. N. Kazantseva, A. Ernepesova, A. Khodjamamedov, O. A. Geldyev, and B. S. Krumgalz, Spectrophotometric Analysis of Iodide Oxidation by Chlorine in Highly Mineralized Solutions, Anal. Chim. Acta, 456, 105-119(2002). 